\title{
OPINIONES DE OTRO POETA DEL 27 SOBRE GARCILASO DE LA VEGA
}

\author{
José Luis Abraham López \\ I.E.S. Hispanidad (Santa FE, Granada)
}

Han sido muchísimos los estudios que sobre Garcilaso de la Vega se han dado a conocer desde distintas perspectivas y orientaciones. Una de ellas, Garcilaso de la Vega visto por los poetas de la Generación del 27, hasta el día de hoy no ha tenido en cuenta los trabajos que otro poeta de dicha promoción -Antonio Oliver Belmás (Cartagena 1903-Madrid 1968)- realizó a lo largo de su intensa carrera literaria.

Sirva como preámbulo una sucinta revisión de lo que fue Garcilaso de la Vega para la mentada generación poética para luego abordar los resultados de los estudios firmados por Antonio Oliver.

De entrada contamos con un factor en contra, como es el de que los trabajos del cartagenero sobre el poeta toledano vienen fechados desde 1944 en adelante (con una sola excepción), mientras que sus camaradas de promoción lo hacen en pleno hervidero de la conmemoración de los baluartes fundamentales que tomaron como canon, quedando en muchos casos manifiesta la fortuna y simpatías que poetas como Garcilaso tuvieron entre dicho grupo. Todos recordamos los versos del poema treinta y cinco "Si Garcilaso volviera / yo sería su escudero" de Marinero en tierra de Rafael Alberti. A la superficie saca el poeta andaluz su herencia más reconocida en "Arión (versos sueltos del mar)", segunda parte de Pleamar (1942-1944): Gil Vicente, Machado, Garcilaso, Baudelaire, Juan Ramón, Rubén Darío, Pedro Espinosa y Góngora. O aquellos versos: "Nadie podrá quitarnos / a la gente de España, / Garcilaso, aquel tuyo / dolorido sentir" del poema número once de "Cármenes", perteneciente al mismo Pleamar. Por último, en Sermones y moradas, "Elegía a Garcilaso" encabeza los versos del poeta toledano "... antes de tiempo y casi en flor cortada". Lejos de una sumisión estéril, en su "Égloga fúnebre" Alberti sólo se parece a Garcilaso en el género que emplea para encauzar su composición.

No se mantuvo al margen Pedro Salinas, quien toma prestado el conocido verso "la voz a ti debida" (que recoge de la Égloga III) para su libro de 1933, y su alumno Luis Cernuda ve en Presagios y Seguro azar una prolongación de "aquella línea de transparente poesía que abre Garcilaso, sin más artificio literario que el indispensable para manifestarse poéticamente"1. Muy similar apreciación emite Jorge Guillén a propósito de Razón de amor, por el regusto que la paz deja con su cadencia². En Homenaje Pedro Salinas rubrica el poema "Dura Galatea" en donde reproduce versos de la Égloga primera.

\footnotetext{
${ }^{1}$ Luis Cernuda, "Pedro Salinas y su poesía”, Obra completa., Barcelona, Siruela, 1994, Vol. 3, Prosa 2, p. 19.

2 Jorge Guillén, "Prólogo a Poesías completas, de Pedro Salinas", Obra en prosa., Barcelona, Tusquets, 1999, p. 576.
} 
En Sonetos espirituales, Juan Ramón Jiménez aplica los modelos que adoptaron Góngora, Lope, Quevedo y Garcilaso, así como en el romancero La flauta y el arroyo.

La celebración en 1936 del centenario de la muerte de Garcilaso de la Vega pone a prueba el interés y los merecimientos de la sensibilidad y destreza de la preceptiva renovadora de Garcilaso. La antología dirigida por G. Díaz Plaja, Garcilaso y la poesía española (1536-1936) da buena cuenta de las colaboraciones de Alberti, Vivanco, Altolaguirre, Rosales, Bleiberg y Miguel Hernández, confirmando que la influencia de su poesía amorosa era por estas fechas un hecho consumado. Así lo demuestra en 1933 Manuel Altolaguirre al publicar su biografía lírica Garcilaso de la Vega, además de ser editor del autor de las Églogas. En la autoconfesión que como pórtico aparece en la Antología de Gerardo Diego éste reconoce sus preferencias por Garcilaso, San Juan de la Cruz y Juan Ramón Jiménez. Cuando en 1939 abandona París para trasladarse a La Habana, donde permanece hasta 1943, Gerardo Diego pronuncia en 1940 una conferencia en dicha Universidad titulada "Enseñanza de Garcilaso".

En la trayectoria zigzagueante de Emeterio Gutiérrez Albelo se aprecia igualmente este influjo. A pesar de comenzar con el versolibrismo en Campanario de la primavera (1930), late en él una disciplina claramente emparentada con la rigidez clásica. En su libro de 1933, Romanticismo y cuenta nueva, bebe de la fuente surrealista empapándose del ritmo cinético de la vida moderna. Le sigue Enigma del imitado (1936), aunque con un fondo agónico existencialista que en los conjuntos poemáticos Cristo de Tacoronte (1944) y Los blancos pies en tierra (1951) se sitúa más próxima a la atracción garcilasista.

Influencia declarada, amor y admiración absorbidos detectamos en Luis Cernuda quien escribe sus primeros poemas bajo este signo garcilasista. Sólo el título de Égloga, elegía y oda habla elocuentemente de esta luz. Además, en Ocnos toma el nombre de Albanio para su protagonista.

Entre las excelencias que Cernuda advierte en Garcilaso coloca al frente el lenguaje sutil y penetrante. Creador de una nueva tradición, lo considera el único inventor de un lenguaje poético en el siglo XVI, "artista consumado antes que poeta inspirado" " ${ }^{\text {. Aunque si queremos }}$ obtener notas menos dispersas, el cuadro más adecuado es aquél que lleva por título "Tres poetas clásicos". A Cernuda Garcilaso le impresiona por lo pulido de su mundo, aquilatando idea y emoción, en contraste con los perfiles de menor íntimo sentido de la realidad de su tiempo. Parece que también la visión que Cernuda tiene de él encaja con la de Pedro Salinas en aquel encuadre de idealización de la realidad:

La obra de Garcilaso es resultado de un conflicto espiritual; la belleza que tiene el mundo en sus versos brota más pura por contraste con la apariencia que ese mundo mismo presentaba para las gentes entre las cuales vivía (Cernuda 1994: 491)

Entre la producción lírica de Gerardo Diego hemos de consignar "Jinojepa de Garcilaso" en Hojas.

Otro poeta murciano postergado, Miguel Valdivieso, además de su poema "El peregrino en sus patrias" de Sino a quien conmigo va, evoca el castillo de Batres donde Garcilaso niño sueña

${ }^{3}$ Luis Cernuda, "Consideraciones provisionales", Obra completa, Barcelona, Siruela, 1994, vol. 2, Prosa 1, p. 247. 
con un futuro, mientras el río -dejándose ver entre las tinieblas de un oráculo- circula por los pies de la fortaleza, al tiempo que ante él aparecen señales de lo que sería su acontecer como ser humano:

\author{
Encuentro de la gloria y la desdicha \\ tan tempranas \\ -oh muerte venerable, \\ oh verde fama- \\ en danubios de tristezas \\ y en islas de confianza... ${ }^{4}$
}

A diferencia de otros poetas de la generación del 27, nunca mostró abiertamente Antonio Oliver una predilección incontestable por Garcilaso. Aunque en sus críticas a la poesía de los años veinte trasluce cierto recelo a la poesía secundada por poetas que se atienen a las formas y oscuridad de Luis de Góngora, tampoco se caracteriza el cartagenero por quebrar el hermetismo ante la ausencia de afirmaciones rotundas.

Oliver toma como punto de partida la vida del toledano para sacar a la luz un aspecto que constituye una nota sustancial en el estilo del cartagenero: se sirve de tres géneros tan distintos como la novela, el teatro y el cuento, ligados con precisión. Aunque aparentemente se revelen como unidos a uno solo de ellos, tienen su mejor momento cuando sobre la narración Oliver Belmás filtra un pasaje de ensoñación, dejando caer sucintamente un comentario de orden historiográfico.

El análisis de estas tres vertientes intentará demostrar que, a pesar de las leyes propias de cada una, el cartagenero acaba cumpliendo con un objetivo que es común: enaltecer y revitalizar el talante humano de nuestro poeta del Renacimiento.

La biografía novelada Garcilaso (capitán y poeta) viene firmada por Andrés Caballero5. Aparece en Ediciones Hesperia de Madrid, ilustrada con nueve dibujos de Francisco Reyes.

No sabemos hasta qué punto le viene bien el título de la colección "Cuentos históricos", dado que en nuestra opinión su autor modula más la técnica hacia lo que llamaremos intento de novelar la biografía de Garcilaso, o en cualquier caso, en una fórmula sintetizadora, biografía novelada que en el siglo XIX tomará un gran impulso. Nos parece importante dejar clara la distinción para situar adecuadamente el género que por primera vez tienta el ánimo emprendedor de Andrés Caballero ${ }^{6}$. Y veremos cómo la fecha en la que situamos el comienzo en tan peculiar género goza de un significado del que su autor no se podrá zafar a pesar de la objetividad con la que afronta tal empresa.

\footnotetext{
${ }^{4}$ Miguel Valdivieso, "El castillo de Batres: (evocación de Garcilaso)", Obra completa., Cuenca, Carboneras de Guadazacón, 1968, p. 133.

${ }^{5}$ Este es el heterónimo que Antonio Oliver empleará en los años de forzado enclaustramiento para seguir de manera incansable su labor literaria. Tomado del personaje de La gitanilla de Miguel de Cervantes, con este nombre firmará los trabajos El escultor Francisco Salzillo y De Cervantes a la poesía, ambos publicados en la Editorial Alhambra de Madrid en 1944.

${ }^{6}$ Permitásenos que en casos muy precisos, y como heterónimo que es, adjudiquemos a Andrés Caballero la plena responsabilidad de las opiniones, volviendo a una sola lámina la duplicidad del auténtico rostro autorial.
} 
Historia, fábula y poesía se entrelazarían en una perspectiva que vence el peligro de una ruptura estética y gana al lector con el conocimiento de una vida digna de contar. De entre la generación de 1927 Oliver encuentra en Manuel Altolaguirre la principal referencia, si queremos contrastar de primera mano cómo dos poetas de la misma promoción emplean parecido perspectivismo en la manera de contemplar el mismo hecho ${ }^{7}$.

Gran parte del contenido oliveriano viene a ser una amplificación de un ensayo que al cabo de los años acometería con la sagacidad crítica de un remozado filólogo. Si Garcilaso: (capitán y poeta) constituye la historia fabulada de Garcilaso, aquella otra de 1965 (Garcilaso de la Vega) será el trabajo crítico de un estudioso de la literatura renacentista.

No esperemos más para marcar el primer rasgo que asoma en Garcilaso: (capitán y poeta), como es la literariedad:

Aquella mañana entraba y salía más gente que de costumbre por la puerta del palacio de Toral, como si algún suceso extraordinario conmoviese la aristocrática mansión. Una puerta es algo de mayor trascendencia de lo que comúnmente se estima: por una puerta, cuando se abre, entran el sol o la niebla, la vida o la muerte, la alegría o la tristeza. La puerta del palacio de Toral, con sus anchos clavos y sus sobrios ataires, no cesaba, desde el amanecer, de abrirse y cerrarse... (Oliver 1944: 3)

Así nos presenta Antonio Oliver la acción de un pueblo que vive a la expectativa del alumbramiento de doña Sancha y que se extiende con aire de profecía: “¡Acaba de nacer un poeta que va a ser gloria de España, y que se llamará Garcilaso! ¡Un poeta que renovará la Poesía!" (Oliver 1944: 5-6). Sin dejar de ser lírico el tono, la veracidad histórica nos está garantizada desde el mismo momento en el que Antonio Oliver posa sobre tierra las circunstancias históricas en las que nace el protagonista, y es cuando entra en acción la reina Doña Isabel. Mucho se podría comentar de la manera con la que el cartagenero introduce este material, pero a nosotros nos basta con sintetizar esta peculiar amalgama que compensa la ausencia de una exhaustiva documentación orientada por una expresión literaria que, pese a permitirle un gran caudal de licencias, acoge sólo aquello que garantiza la verosimilitud. Este será uno de sus principios críticos consagrados, aunque como veremos también sabrá adaptarse a la naturaleza del texto literario haciéndose cargo de la imposibilidad de aplicar un método universal.

De esta manera, sin llegar a olvidar Oliver cuáles son sus deberes como historiador, la Historia crece entre un aire novelesco imbuida progresivamente en las circunstancias que envuelven al personaje principal de la acción y que ayudan a comprender cuál es su relación con el mundo. Él mismo nos lo viene a confirmar en las siguientes líneas:

\footnotetext{
${ }^{7}$ Nos estamos refiriendo a Garcilaso de la Vega, publicado en 1933, número diez de la colección "Vidas extraordinarias". Todos los rasgos hasta aquí señalados se pueden aplicar por igual a este interesante trabajo del malagueño.
} 
[...] La función esencial del biógrafo no radica en ceñirse secamente a la realidad. Sobre los hechos verdaderos, pilares naturales de toda biografía lo que debe hacer un buen biógrafo es "interpretar" y revitalizar el pasado... ${ }^{8}$

De lo hasta aquí desarrollado se deduce que la concepción del género en Oliver tiene más que ver con la credulidad que con la verbosidad ${ }^{9}$. No antepone la poesía a la realidad, como tampoco se rinde ante el éxito narrativo por sacrificar la expresividad propia. Ya tenemos despejado el logro crucial: cómo el poeta consigue convertir en apacibles y dorados todo un infinito número de datos que se le aparecen por doquier.

En cambio, habría que hacer constar algunas omisiones, como en el caso del enamoramiento de Garcilaso con Isabel Freyre, porque el comentario que en este sentido predomina en el trabajo de Oliver Belmás es el recuerdo permanente de Elena de Zúñiga y sus hijos.

Como ocurrirá en su pieza teatral Morir sino sin miedo que luego abordaremos, en Garcilaso: (capitán y poeta) Antonio Oliver personifica las virtudes:

En Batres, de paisaje muy parecido al de los cigarrales toledanos, con sus olivos, sus chopos, sus negrillos y sus caseríos, entre castellanos y andaluces, el hijo de doña Sancha corría de la mano de dos niñas preciosas, dos hadas diminutas que se llamaban la Satisfacción y la Felicidad... (Oliver 1944: 9)

A través de estos comentarios estimamos que también la forma narrativa, según convenga a la eficacia de sus propósitos, se empapa de unas fórmulas colindantes a la lírica.

Con la intención de abarcar distintas esferas cuya omisión complicaría en exceso la comprensión total del hecho literario, hay una linterna que Oliver Belmás considera mágica como es la Historia. Teniendo presentes los efectos benéficos de ésta, el escritor enhebra la acción con el referente histórico, bien para contextualizar, bien para sumergirnos de manera más racional y entender las circunstancias que llevan a Garcilaso por cada una de sus vicisitudes. Precisamente, también la Historia sufre una personificación, a propósito de la labor que el toledano llevó a cabo como instructor del emperador Carlos $\mathrm{V}$ en sus lecciones de español:

[...] Siempre en mis largos viajes me acompañarás, y yo haré una hora para esto. Podéis retiraros por el momento, Enríquez; y lo mismo vosotros, Velasco y De Haro. Vos, amiga mía, permaneced con nosotros.

[...] Eran ya el profesor y el alumno. Garcilaso dictó en flamenco una palabra: el Emperador escribió. Garcilaso tomó entonces ora pluma y debajo puso: "España", nombre que pronunció en voz alta, deletreándolo con amorosa lentitud. El Emperador lo repitió. Escribiendo y pronunciando esta y otras palabras, transcurrieron casi dos horas. La dama aludida, que no era

\footnotetext{
8 Antonio Oliver Belmás, "Isidoro Maiquez, de José Vega", Raíz: (cuadernos literarios de la Facultad de Filosofia y Letras), 2 (1948), pp. 23-24.

${ }^{9}$ En este sentido nos recuerda la biografía que Antonio Espina -entre otras del mismo género- escribió de Luis Candelas.
} 
otra que la Historia, los estuvo contemplando silenciosa, no sin sonreir de cuando en cuando, con máxima dulzura (Oliver 1944: 22)

Entre las suavidades del tono lírico y los datos que arrastra la elocuencia histórica, de vez en cuando Oliver inserta una estampa de la vida cotidiana. Para mostrar un caso de esta intrahistoria acudamos al pasaje en el que Antonio Oliver narra la victoria de Carlos V en Italia, cuando hace prisionero al monarca enemigo. Tras este cautiverio, en la página veinticuatro recoge la canción popular que alude al mismo, transcribiendo la versión italiana y la española.

Apenas entra Oliver Belmás en terrenos ajenos a la biografía novelada, aunque encuentra tiempo para hacer alguna incursión por la galería literaria de nuestro Renacimiento, de manera que ya apunta la rivalidad que existió entre Garcilaso de la Vega y Cristóbal de Castillejo y el prólogo que aquél realizó a la traducción de Boscán de El Cortesano de Castiglioni.

En cuanto a las fuentes bibliográficas manejadas, llama la atención el hecho de que sea en esta obra, que es la que más justificada puede tener la ausencia de un aparato bibliográfico, donde el cartagenero adjunte un listado con los diez libros consultados. Este repertorio sirve para suponer idénticas apoyaturas en trabajos que le siguen a éste como Garcilaso de la Vega ${ }^{10}$.

Redactado de forma más copiosa y madura en sus planteamientos y trasfondo, Garcilaso de la Vega ve la luz bajo el sello de Nuevas Editoriales Unidas, constituyendo el tomo primero de la colección "Genio y figura", con un apéndice antológico de una selección de la obra poética de Garcilaso.

Hemos de comentar en primer lugar que Antonio Oliver resuelve favorablemente el problema que se le plantea a quien pretende hincar el diente a un estudio que acoja por igual erudición y amabilidad expresiva. En definitiva, cómo combinar amenidad, belleza y didactismo sin caer en el esteticismo, ramplonería y pesadez.

En la primera parte de Garcilaso de la Vega Antonio Oliver vierte una semblanza sobre la figura humana del militar y diplomático, auténtico paradigma del hombre cortesano. Hace especial hincapié en la faceta de españolización durante su estancia en Nápoles, así como la labor de enseñanza de la lengua española en el reinado de Carlos V, amanuense del Emperador si respetamos uno de sus capítulos.

Pero lo verdaderamente interesante es calibrar de modo objetivo las opiniones particulares que, de su obra sobre todo, tiene el cartagenero.

A poco de comenzar la primera parte, y a propósito de la faceta musical de Garcilaso, perfecto dominador de la vihuela y clavicímbalo (donde hallamos envuelto el doble juego del ritmo del verso y la cadencia instrumental), Antonio Oliver argumenta que:

Antes que Rubén Darío es Garcilaso el gran poeta que coloca al verso castellano en la frontera misma de la música, de la que hoy los poetas actuales, ellos sabrán sus razones, lo han destronado pasajeramente (Oliver 1965: 25)

Tampoco este rasgo le pasa desapercibido a Manuel Altolaguirre:

\footnotetext{
${ }^{10}$ Antonio Oliver Belmás, Garcilaso de la Vega, Madrid, Nuevas Editoriales Unidas, 1965, pp. 25-26.
} 
[...] Versos hay en Garcilaso que se adelantan a los de Góngora, a los de Rubén Darío, por citar dos nombres representativos de tendencias renovadoras:

"Hinchan el aire de dulce armonía" es un endecasílabo modernista perfecto... ${ }^{11}$

No resulta extraño encontrar alusiones de Oliver sobre el oído musical de este perfecto cortesano, hasta llegar a decir que por su especial sentir la poesía del Danubio es un precursor de Schubert, al estar próxima la canción escrita durante su destierro en la isla de Schut de la música pura.

Otro rasgo destacado en las opiniones de Antonio Oliver sobre Garcilaso es el de reconocer en éste tres siglos antes lo que sería el sentimiento romántico,

aunque en el toledano por su culto a la forma y por su contención y equilibrio espiritual, todavía no lo sea.

Tenemos que hacer constar también que la forma con la que Antonio Oliver se mueve por el mundo garcilasiano puede dar la impresión de atender a un confinamiento en el relativismo. En cambio, con una incursión particular en cada uno de los trabajos del cartagenero vinculado con el poeta toledano vemos con precisión que se encuentra más cerca de un perspectivismo aglutinador.

Por encima de las opiniones de Menéndez Pelayo, Navarro Tomás y Rafael Lapesa sobre la canción cuarta, en Garcilaso de la Vega Oliver centra su fuerza en una rara excepción en la obra garcilasiana: el anhelo de la posesión erótica y la repugnancia interna que se siente después del desear. Oliver Belmás llega incluso a emplear la palabra "filólogo", sobre todo a partir del estudio de una epístola que Garcilaso remite a doña Jerónima Palova de Almogavar, cuando cuenta los pormenores de la traducción de su amigo Juan Boscán de El cortesano de Castiglione, y en donde Garcilaso pone énfasis en el mérito del trabajo del catalán en cuanto a que "no se ha de atar al rigor de la letra, como hazen algunos, sino a la verdad de las sentencias".

Una señal indicativa que complementa a la pura narración - que Oliver detecta y le cautivala constituye el hecho de que el modulado castellano que emplea Garcilaso está destinado sobre todo a la subjetividad y al lirismo.

Al margen de apreciaciones más profundas el trabajo del cartagenero se recrea en narrar la controversia entre un defensor de la preceptiva clásica como Cristóbal de Castillejo y un poeta que apuesta y se implica en la renovación de las formas. Veamos con qué ponderación Antonio Oliver encuentra cobijo en una serie de fórmulas binarias que enriquecen los matices, y en la que él mismo toma parte:

Toda la lucha de Castillejo y su cohorte será vana. A un capitán aguerrido en armas como Garcilaso no le asusta la guerra literaria. Porque, además, la posición de Castillejo era injusta. El endecasílabo no iba a acabar con el octosílabo; las formas métricas renacentistas no exigían la supresión de las tradicionales. Lo que se trataba era de hallar nuevas dimensiones y nuevas casas para el verso. Porque el verso es a la poesía lo que el cuerpo es al alma. Si ésta informa nuestra frágil mansión corporal, la poesía informa al verso, lo habita y anima y lo esplende, y

\footnotetext{
${ }^{11}$ Manuel Altolaguirre, Garcilaso de la Vega, Madrid, Espasa-Calpe, 1933, p. 87.
} 
no exige de él sino ojos por donde mirar, oídos por donde escuchar, labios por los que besar. Los versos endecasílabos coexistieron con los octosílabos; los tercetos, sextas rimas, octavas y sonetos, con las letrillas, glosas, villancicos y ovillejos. Se llegó a una coexistencia pacífica, culta y civilizada. Pero Castillejo perdió el combate en Viena y Garcilaso lo ganó en Nápoles, en Sicilia, en Roma, al calor de los humanistas amigos y de los poetas italianos, que lo admiraban y valoraban (Oliver 1965: 16-17)

Un nuevo rasgo que atrae la atención de Oliver tiene que ver con el ámbito amoroso de Garcilaso de la Vega. En este sentido, la mayor parte de la crítica ha coincidido en que la figura de la dama de compañía de Isabel de Portugal es más reincidente que la conyugal de Elena de Quiroga, y tanto es así que pocos reconocen un solo poema dedicado por Garcilaso a su primera esposa. En cambio, sin apurar su teoría y dejándola abierta a la discusión, Oliver sí ve en el soneto que empieza "Un rato se levanta mi esperanza" un fondo amatorio donde la protagonista es Elena, cuando el poeta, exiliado amante implacable, la rememora en la prisión en la isla de Schut. Pero no acaba aquí la precisión, sino que va más lejos al decir que

tal vez sea el único soneto metafísico de Garcilaso, a quien se le ha acusado de no estar religado a la creencia, al menos en su propia poesía (Oliver 1965: 22)

lo cual pone en duda la opinión de Azorín cuando juzga al toledano en estos términos:

En la obra de Garcilaso no hay ni la más pequeña manifestación extraterrestre. Todo es humano en él; y lo humano ha sabido expresarlo con una emoción, con un matiz de morbosidad, con un lejano ideal, que nos cautivan y llegan al fondo de nuestro espíritu ${ }^{12}$.

Manuel Altolaguirre está del mismo lado que Oliver:

Es curioso notar aquí la falta de fervor religioso que encontramos en un poeta católico como Garcilaso. Sin embargo, no fue tan disparatada la interpretación mística que de sus obras se hizo más tarde. El autor de esta interpretación veía claramente oculta una remota y posible relación entre los sentimientos humanos del poeta y la formación religiosa de su alma (Altolaguirre 1933: 67)

Esta afirmación contrasta con la de Pedro Salinas, quien no tiene dudas sobre la nula presencia de Elena de Zúñiga en toda su obra poética. Esto es lo que dice el madrileño:

[...] Este matrimonio, más que de amor, parece de conveniencia social. Ni una traza de amor conyugal se encuentra en su poesía amorosa. La figura de su mujer no aparece jamás en su lírica... ${ }^{13}$

Tampoco pierde de vista este aspecto Dámaso Alonso:

En cambio, Doña Elena de Zúñiga está totalmente ausente de los versos de su esposo... ${ }^{14}$

\footnotetext{
${ }^{12}$ Azorín, "Garcilaso", Obras escogidas, Madrid, Espasa-Calpe, 1998, T. 2. Ensayos, pp. 1276-1277.

${ }^{13}$ Pedro Salinas, "La idealización de la realidad (Garcilaso de la Vega)", Ensayos completos., Madrid, Taurus, 1983, T. 1, p. 228.

${ }^{14}$ Dámaso Alonso, "Sobre Garcilaso", Obras completas, Madrid, Gredos, 1972, Vol. II, p. 524.
} 
Antonio Oliver se ha planteado una biografía novelada, para la cual estima que hemos de compartir el tiempo presente de la figura del poeta. Valga un solo ejemplo. Una mañana del mes de agosto de 1534 don Pedro de Toledo al quedarse a solas con Garcilaso, así le habla de un asunto serio:

-Querido Garcilaso -vino a decirle probablemente el virrey-, Solimán, que por tierra no se atreve a medir sus armas con las nuestras, quiere plantearnos la lucha en el mar... (Alonso 1972: 27)

aunque mucho más esclarecedor para mostrar el efecto de omnisciencia, nos parece este otro pasaje, ya en Túnez en pleno mar a bordo de la nave capitana:

[...] Garcilaso, en la proa y apoyado sobre la borda, abría su alma al ensueño, ajeno momentáneamente al papel que allí desempeñaba. Alternativamente miraba al mar y al cielo. En su abstración no sabía si navegaba sobre las aguas o sobre las estrellas. Estas eran las mismas que brillaban frente a su ventana en las noches de Nápoles... (Alonso 1972: 38)

Veamos ahora hasta qué punto llegan las concomitancias de este pasaje de Oliver con aquel otro que Manuel Altolaguirre incluye en el capítulo "La flor de Gnido" de su trabajo titulado también Garcilaso de la Vega. Dice el autor de Las islas invitadas:

[...] Garcilaso, sobre cubierta, libre como las nubes y las ondas, dejaba a Dios el cuidado de remediar tanta injusticia. Por educación y por temperamento, su posición ante la vida era la de un espectador de lo irremediable. El acompasado chocar de los remos rimaba bien con el hondo sentimiento de su desesperación. Mientras más repetido éste fuera más cercano estaba su destino. A él le llevaban los remos de los forzados y sus propios dolores (Altolaguirre 1933: 184-185)

Abordemos una última comparación, para comprobar la manera que Oliver y Altolaguirre tienen de describir el fallecimiento del poeta. He aquí, bajo el rótulo "La torre de Muey", cómo lo describe el cartagenero ante la resistencia de los franceses que impedían la retirada española:

[...] La torre, difícil de escalar, tenía unos dieciséis metros de altura. El maestre de campo vio que la noche se echaría encima y que la torre no sería sometida. Por eso, en un rasgo que a él no le correspondía, sino a sus soldados, ágil, nervioso, excediéndose equivocadamente en su deber, ordenó a un escudero suyo que colgase una escala de la torre. Entonces Garcilaso, sin capacete protector, con la hermosa cabeza descubierta y sólo la espada y la rodela, se lanzó el primero al asalto. Detrás de él subiría todo el ejército, pensó. Unos metros le faltaban al heroico asaltante para coronar las almenas cuando, desde éstas, los franceses arrojaron una enorme espuerta de piedras, que derribaron al poeta, el cual cayó al foso mortalmente herido (Oliver 1965: 15)

que bien podríamos situar al lado de esta deliciosa recreación de Altolaguirre en el tramo final del capítulo "La muerte de Garcilaso":

[...] Avanzaba solo, en silencio. Cuando estaba cerca del foso recibió las primeras heridas de las flechas contrarias. Parecía un enamorado víctima de unos traviesos amorcillos. Los niños reían, se burlaban del que con tanta entereza continuaba avanzando. Cerca de las paredes descabalgó, y aprovechando una cuerda que colgaba del muro intentó subir a lo alto. En la pierna tenía clavada una flecha, otra en el costado. Ni el dolor ni la sangre le hicieron 
desmayar. Ya estaba a pocos metros de las almenas cuando un Polifemo gigante, un cíclope monstruoso, celoso de las mismas saetas que adornaban su alma de Acis, levantó una gran piedra en los aires y la desplomó sobre su víctima... (Altolaguirre 1933: 219)

Con este pasaje volvemos a uno de los cordajes novelescos que refuerzan la expresión "biografía novelada" pues, en el caso del escritor cartagenero, quiebra esa vaga lejanía que mantiene con el biografiado para asomarse a él hasta meterse en su piel, tornando traslúcidos un conjunto de signos que se ven acompañados de múltiples actitudes, gestos, palabras...; esto es, le aplica un tratamiento de personaje novelesco.

A pesar de estos interesantes mecanismos internos en la narración, sin duda alguna el aspecto que más atención merece tiene que ver con la segunda parte de este opúsculo. Para desentrañar metódicamente la obra del poeta toledano, Antonio Oliver parte de un plan rigurosamente diseñado con el fin de inmiscuirse entre los entresijos del estilo, los temas y el vocabulario.

A través de este singular periplo, como decimos, Oliver aborda el comentario de la Égloga II, deteniéndose en aquel punto en el que Nemoroso relata a Salicio cómo curó de su pasión amorosa gracias al monje italiano Severo, encargándose él mismo de la curación de Albanio. Para Rafael Lapesa este pasaje se aleja del bucolismo de la égloga debido al tono de panegírico que Garcilaso aplica hacia la casa de Alba, pues Severo fue preceptor de don Fernando de Toledo, duque de Alba. Así lo leemos:

[...] Pero la atadura externa no remedia la falta de íntima cohesión: bucolismo y panegírico se despegan, y aun dentro de lo pastoril, los quinientos versos inspirados en Sannazaro dan la impresión de forzado alargamiento ${ }^{15}$

aunque reconocemos que tampoco la justificación que arguye Oliver se caracteriza precisamente por su convicción. Sólo alude a la ayuda que dicha casa aristocrática prestó en los momentos de su arresto en Tolosa y destierro en Schut (Oliver 1965: 66-67).

Otro aspecto de discordia tiene lugar al apoyar Oliver Belmás con frases calificativas lo que la crítica ha creído entender en la conocida canción cuarta. Para Menéndez Pelayo significa la elegía del alma. Navarro Tomás se inclina a pensar en la lucha entre la Razón y el Deseo, mientras que para Rafael Lapesa "el raudal del sentimiento, inestable y alógico, se desborda, prestando tintes sombríos al análisis de estados anímicos" (Lapesa 1985: 77). Y nos queda la del cartagenero:

Lo que en la canción cuarta, por rara excepción a lo largo de su obra, presenta Garcilaso es el anhelo de la posesión erótica y la repugnancia interna que se siente después del desear (Oliver 1965: 89)

Por encima de la penetración psicológica, el aspecto que a Oliver atrae de Garcilaso es la delicadeza del lenguaje "que se coloca en sus momentos felices en la frontera de la mística".

${ }^{15}$ Rafael Lapesa, La trayectoria poética de Garcilaso, Madrid, Alianza, 1985, p. 103. 
Si bien los rasgos que Antonio Oliver enaltece son los mismos que subraya la crítica especializada, no está de más, aun tratándose de un elemento bastante común, comentar algunas de sus opiniones:

Este poeta renacentista adivina el sentimiento romántico, aunque él, por su culto a la forma y por su contención y equilibrio espiritual, todavía no lo sea (Oliver 1965: 85)

Pero es llegado al cambio de registro que presenta la perspectiva temática, cuando Oliver adopta todos los visos de filólogo que tanto nos recuerda -de leerlo en su totalidad- a los magníficos estudios estilísticos de Dámaso Alonso. No tenemos más que transcribir el comentario que le merece la conocida octava séptima de la Égloga III:

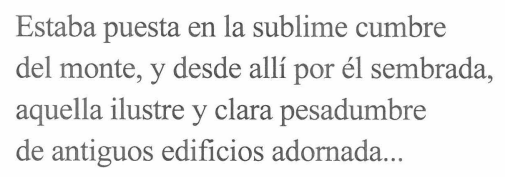

Mas si esto lo consigue Garcilaso con el encabalgamiento, la nobleza de Toledo la describe con un sustantivo abstracto, "pesadumbre", y dos epítetos: "ilustre y clara". Es curioso observar, además, que para Garcilaso la montaña toledana es ascendente y para Góngora "precipitante". Como si uno la hubiese contemplado desde el valle y otro desde la cumbre. Según Dámaso Alonso, Toledo es para Garcilaso en la égloga tercera

\section{La más felice tierra de la España}

Pasemos a otro de los referentes garcilasianos en la obra de Antonio Oliver como lo es Morir sino sin miedo. Lo mismo que Pedro Salinas adoptara el verso garcilasiano La voz a ti debida de la Égloga III, Antonio Oliver hace uso de un verso de la Canción III, "morir sino sin miedo"16 como título para su única pieza dramática, terminada de escribir en Lorca en plena Semana Santa de 1943. Desde el mismo momento en el que en esta obra el autor se adelanta desenmascarando al destinatario, tenemos a tiro el fin moralizador y pedagógico: "A la juventud española, con plena fe en sus destinos". Una primera referencia a este proyecto teatral la hallamos en Las conversaciones de Andrés Caballero ${ }^{17}$, donde el cartagenero habla a su alter ego cervantino del intento por dar forma dramática a su idea de llevar a escena un pasaje de la vida de Garcilaso de la Vega. Una de las razones que guían su empresa es la de ponerse en guardia contra la mediocridad del teatro, captar su atención sobre un género moderno y nuevo aprovechando las ventajas que frente a éste ofrece el cine. En este sentido, Morir sino sin miedo no respetará las reglas clásicas de tiempo y espacio.

Resulta francamente complicado colocar bajo un género esta pieza. Por sus fines moralistas y el papel predominante de la alegoría y las personificaciones de las virtudes y los vicios, está más cerca de las moralidades de la tradición literaria medieval y autos sacramentales de Calderón que del teatro de Cámara; incluso comparte más calideces con el "auto lírico" o "misterio profano" que con la comedia o el drama. El fin de esta representable biografía

\footnotetext{
${ }^{16}$ Publicado en la Editorial Doncel de Madrid en 1961.

${ }^{17}$ Antonio Oliver Belmás, Obras completas, Madrid, Biblioteca Nueva, 1971, pp. 748-749.
} 
dramática es el de aleccionar a la juventud mediante un vivo patriotismo no exento de belleza y esencialidad. Para salvar la vulgaridad que impone el género, Antonio Oliver recurre a símbolos que tendrán peso específico en la escena, y así conviven abstracciones con personajes históricos como el César Carlos, el Marqués de Lombay, junto a literarios como Salicio y Nemoroso, además de humanos como la madre de Garcilaso, su sobrino, el duque de Alba, etc.

Antonio Oliver propone una serie de cuestiones técnicas de entramado y tramoya para dar mayor realce. Insiste en la fidelidad al vestuario y escenografía, mientras que los personajes literarios deben atenerse a su simbolismo, y así muestra su conformidad para que el Espíritu pueda ser representado por la figura del "Ángel de la Oración" del escultor murciano Francisco Salzillo:

La figura del Emperador ha de encarnarse con el mayor respeto y propiedad. La del Marqués de Lombay ha de aparecer todavía en traje militar, pero el actor ha de acentuar psicológicamente la transición después. Interesantes en su fidelidad representativa deben ser las figuras de Juan Boscán y de Garcilaso de la Vega. La actriz que represente a la madre de los Garcilaso ha de poner toda su sabiduría en expresar la tragedia de cada uno de sus hijos... (Oliver 1971: 809)

Frente a la libre diversidad de posibilidades Oliver Belmás se atiene a la fidelidad histórica. La localización topográfica cuenta con distintas escenificaciones, desde las orillas del Tormes, en la villa de Alba, pasando por el Palacio de Batres, el jardín y el palacio del Duque de Alburquerque, un mesón de Toledo, la celda de la isla de Schut, una ciudad italiana donde el poeta Garcilaso se repone de sus heridas de guerra, la torre de Muey en Túnez y Niza. La acción transcurre desde 1520 con la guerra de las Comunidades hasta el fallecimiento del renacentista en 1536

Desde el punto de vista literario, lo interesante de este trabajo de Antonio Oliver transcurre a partir del confinamiento de Garcilaso en la isla de Schut, en donde la Poesía hace de nuevo acto de presencia, comparada siempre con una dama que nunca puso empeño de olvido hacia el poeta. Mientras tanto, entra en liza la otra contienda, la literaria, entre quienes defienden lo tradicional frente a los partidarios de enriquecer la versificación castellana introduciendo ritmos italianos. En este sentido, el Romance, la Redondilla, la Cuarteta, la Cuaderna Vía, la Copla de Arte Mayor, el Villancico y la Glosa intentan doblegar la vigilancia de los centinelas, repitiendo a modo de estribillo:

$$
\begin{aligned}
& \text { ¡Muera, muera! } \\
& \text { ¡Viva, viva Castillejo! }
\end{aligned}
$$

Antonio Oliver da carta de naturaleza de personaje al concepto de Matria, y le hace compartir una de las escenas finales junto al Espíritu, la Noche, la Pobreza y la Virtud.

Si nos detenemos un momento en la génesis y el contenido de Morir sino sin miedo, nos damos cuenta de hasta qué punto trasciende el sentido literario, puesto que el sufrimiento tiene un rostro, separados por cinco siglos; soledad consecuente con una actitud vital en Garcilaso de la Vega como en Antonio Oliver.

Nacida en la obligada reclusión de la inmediata posguerra, hubo que esperar hasta marzo de 1963 para que Oliver Belmás viera cumplido su deseo de ver representada esta biografía 
dramática, cuya puesta en escena corrió a cargo de la compañía de Modesto Higueras, aunque la mayor ilusión del autor era la de escenificarla en el mismo castillo de Batres ${ }^{18}$.

Junto a estas obras comentadas debemos situar el poema "Desventuras póstumas de los dos Garcilasos" ${ }^{19}$. En él, Oliver centra su atención en la famosa fuente de Batres donde transcurrió la infancia del "primer poeta militar de España". Antonio Oliver consiguió por insistentes requerimientos que la Academia de Bellas Artes de San Fernando lo declarara monumento nacional. En otra composición, fechada en Madrid el 7 de septiembre de 1967, insiste en el abandono en que dicha fuente ha caído:

$$
\begin{aligned}
& \text { La fuente de Garcilaso } \\
& \text { ya no baja al río de Batres; } \\
& \text { que es una fuente perdida } \\
& \text { que ya ni corre ni nace. } \\
& \text { Las ninfas ya no se miran } \\
& \text { en sus límpidos cristales; } \\
& \text { y para beber en ella } \\
& \text { no se para el caminante. } \\
& \text { Ya no se escucha el murmullo } \\
& \text { de su voz trémula y suave; } \\
& \text { sólo el gemir de las ramas } \\
& \text { cuando las azota el aire. } \\
& \text { Yo ya no quiero volver } \\
& \text { donde tanto estuve antes; } \\
& \text { porque una fuente sin agua } \\
& \text { es como un cuerpo sin nadie. } \\
& \text { Ya no le diré requiebros } \\
& \text { a esta amada susurrante; } \\
& \text { ni con mis labios ardientes } \\
& \text { ya nunca podré besarle. }
\end{aligned}
$$

Antonio Oliver anima a su amigo Juan Antonio Cabezas a iniciar una campaña periodística a favor de su restauración, y éste en un artículo publicado en $A B C$ da noticia de tal acontecimiento ${ }^{20}$, transformado entonces el castillo de Batres en una escuela de Jardinería y Paisajismo.

Muy parecido al arriba trascrito es este otro de fecha anterior, 21 de marzo de 1959, que lleva por título "A la fuente de Batres":

Aquí bebió Garcilaso

\footnotetext{
${ }^{18}$ Por la información que tenemos, parece que Oliver quedó muy contento de su obra dramática. Desde California, el profesor Donald Fogelquist intentó hacer interesar esta pieza a distintos productores de Hollywood, pero en ninguno de los casos surtió efecto.

${ }^{19}$ Antonio Oliver Belmás, "Desventuras póstumas de los dos Garcilasos", Folia Humanística, 1966 (45), pp. 727730 .

${ }^{20}$ Antonio Oliver Belmás, "Mentidero de la Villa", en $A B C, 1973$, p. 56.
} 


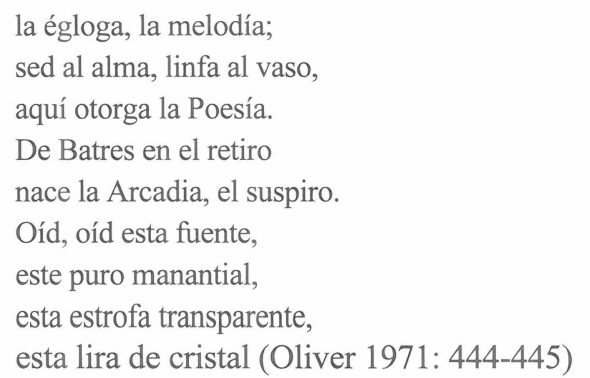

En conclusión, esta trilogía oliveriana sobre la vida y obra del toledano forma una perfecta geometría como lo atestiguan los datos, expresiones y formas lingüísticas que se vierten de uno a otro. Así, Garcilaso de la Vega, la más seria en cuanto que abarca aspectos más técnicos de adiestrado filólogo, parece ser el resultado de una revisión de las anteriores. Es importante en este sentido insistir en la consecuencia de perseguir objetivos distintos. Frente a ésta, Morir sino sin miedo está destinada a aleccionar a la juventud con un fin patriótico, así como sucede con Garcilaso (capitán y poeta), mientras que Garcilaso de la Vega (no olvidemos que fue escrita en el centenario de Garcilaso) está más orientada a la erudición. 